\title{
Corrigendum: Calorie restriction for long-term remission of type 2 diabetes
}

Author: Roy Taylor ${ }^{\mathrm{A}}$

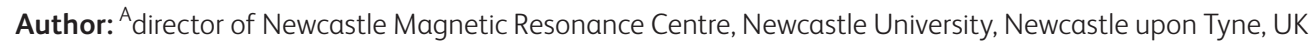

Address for correspondence: Professor Roy Taylor, Newcastle University, Magnetic Resonance Centre, Campus for Ageing and Vitality, Newcastle upon Tyne, NE4 5PL, UK. Email: roy.taylor@ncl.ac.uk

The paper was adapted from the lecture provided by Prof Roy Taylor for the Horizons in Medicine conference 2018.

The internationally accepted threshold for diagnosis of diabetes was reported as $\mathrm{HbA} 1 \mathrm{c}>43 \mathrm{mmol} / \mathrm{mol}$ in error, this has been corrected to $\mathrm{HbA} 1 \mathrm{c}>48 \mathrm{mmol} / \mathrm{mol}$.

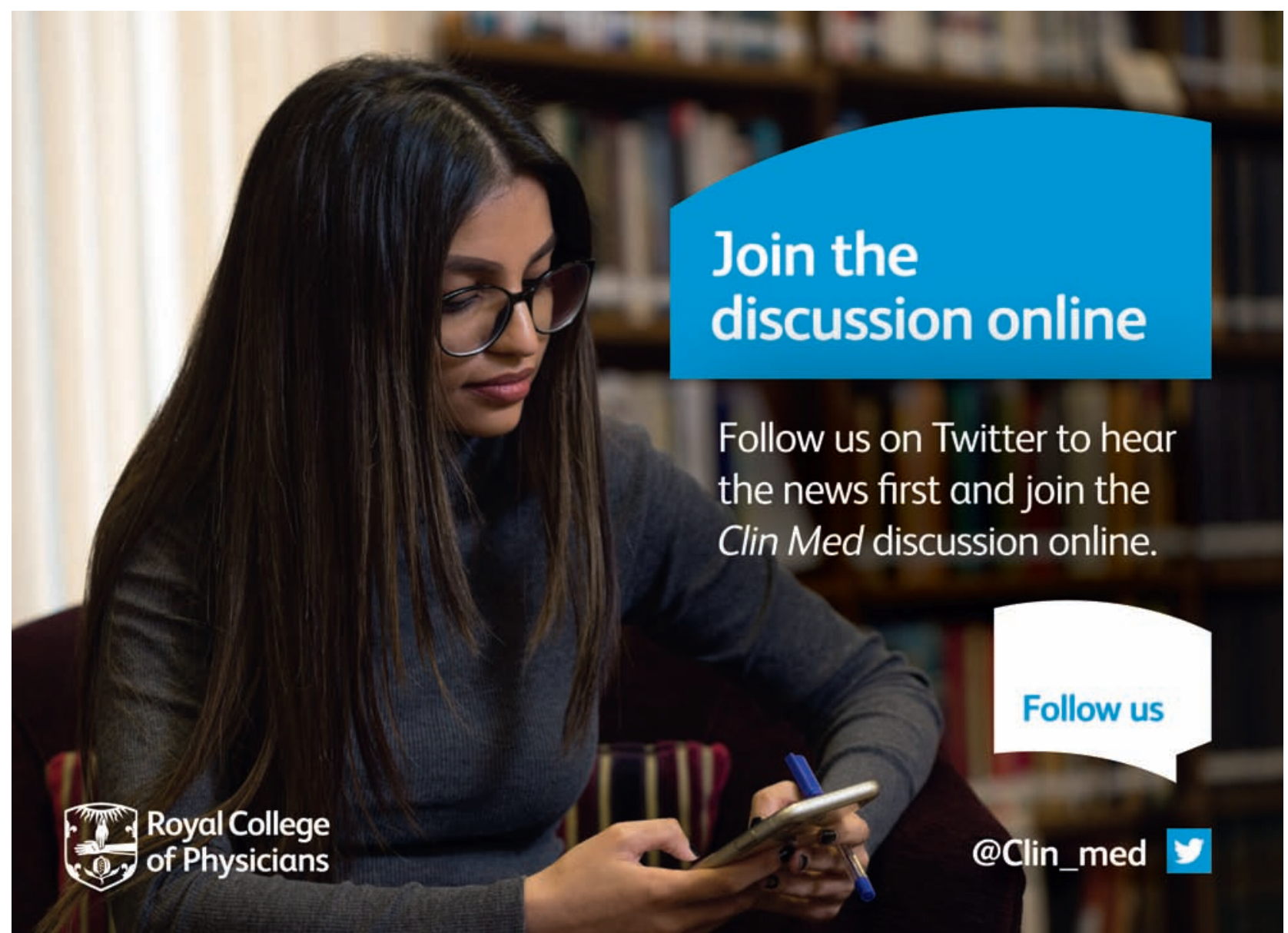

